Supporting Materials:

\title{
Studies of Langmuir-Blodgett Films of an Ion Pair Metal Complex Containing Eu(III)-Ru(II) Dual Chromophores
}

Li-Hua Gao, Ke-Zhi Wang," Li Cai, Hao-Xu Zhang, Lin-Pei Jin, Chun-Hui Huang, and Hong-Jun Gao 


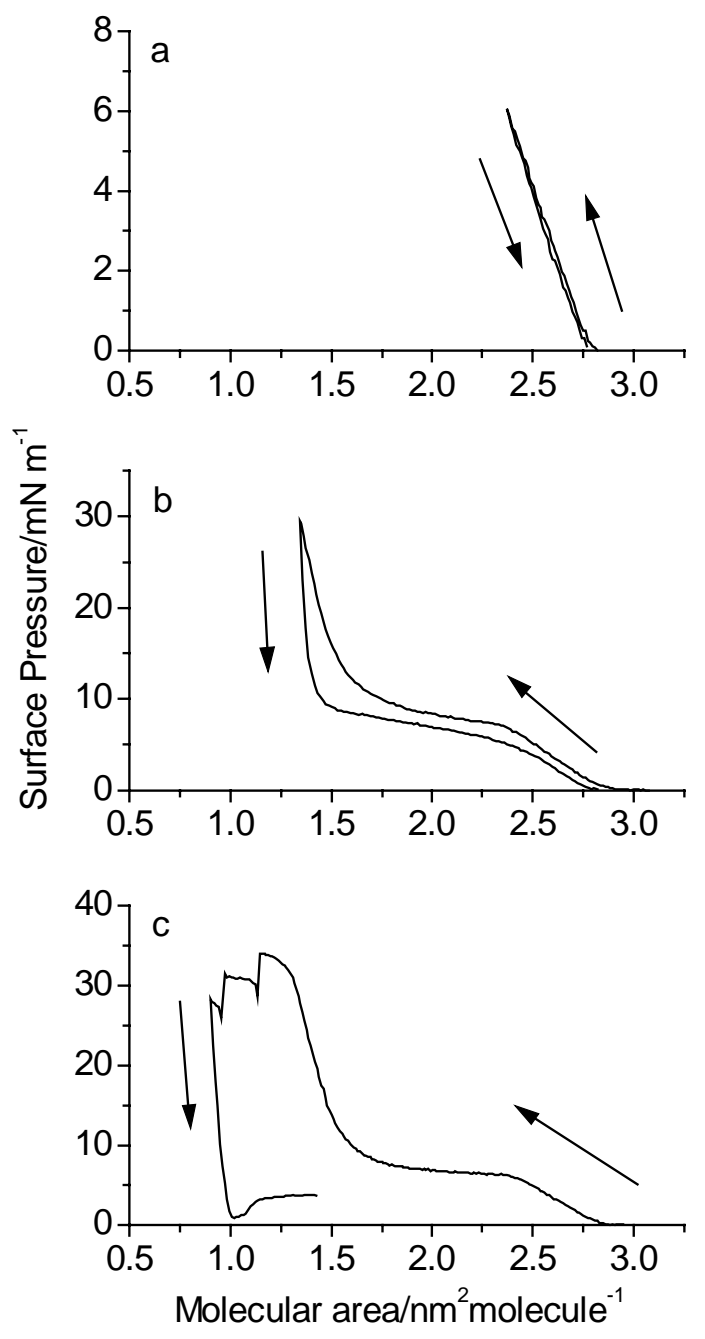

Figure S1. The compression-expansion isotherms at reversal pressures of $6 \mathrm{mN} \mathrm{m}^{-1}$ (a), $30 \mathrm{mN} \mathrm{m}^{-1}$ (b) and $35 \mathrm{mN} \mathrm{m}^{-1}$ (c). 


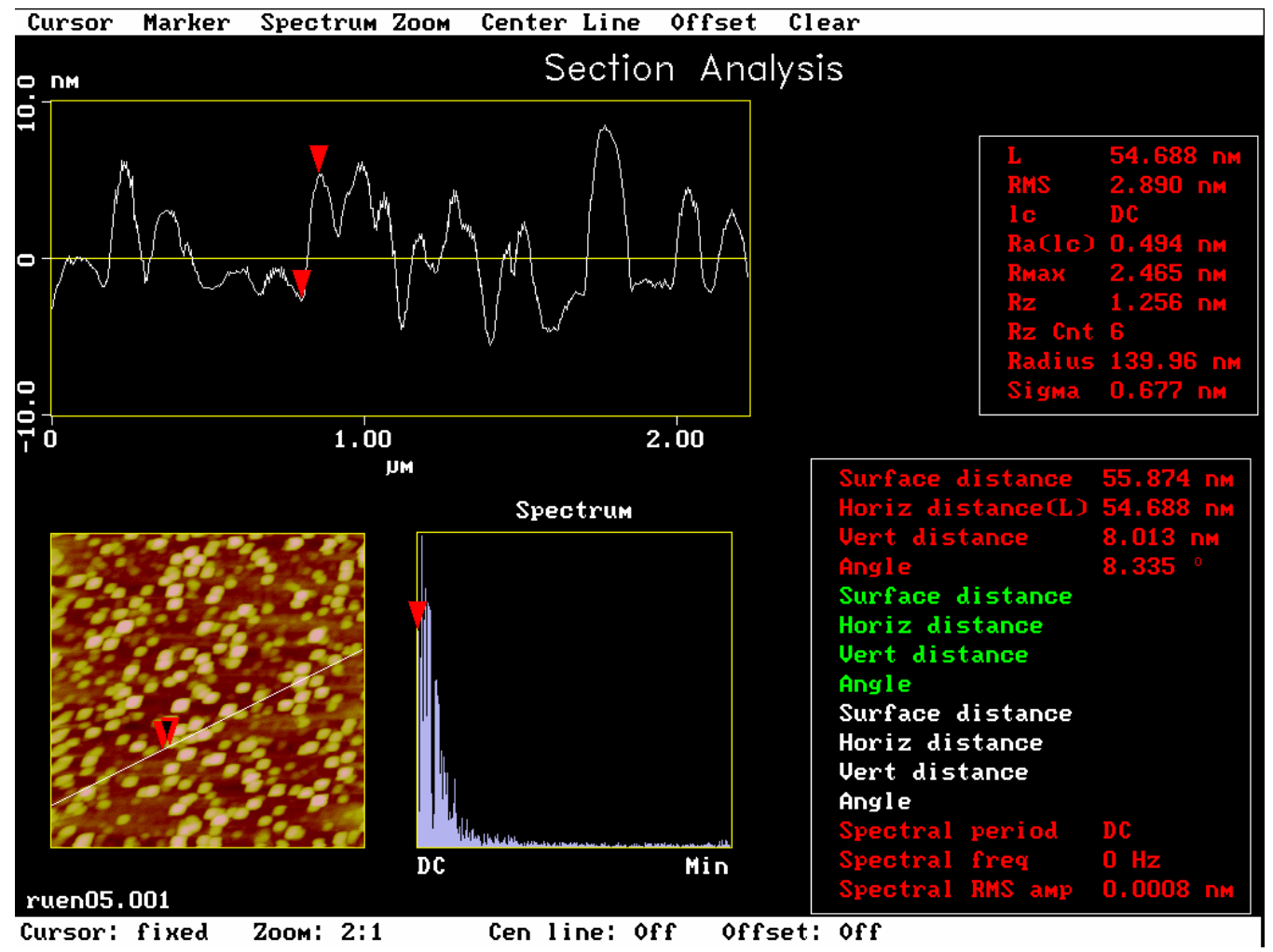

Figure S2. An AFM image of monolayer film of 1 deposited at $5 \mathrm{mN} \mathrm{m}^{-1}$. 


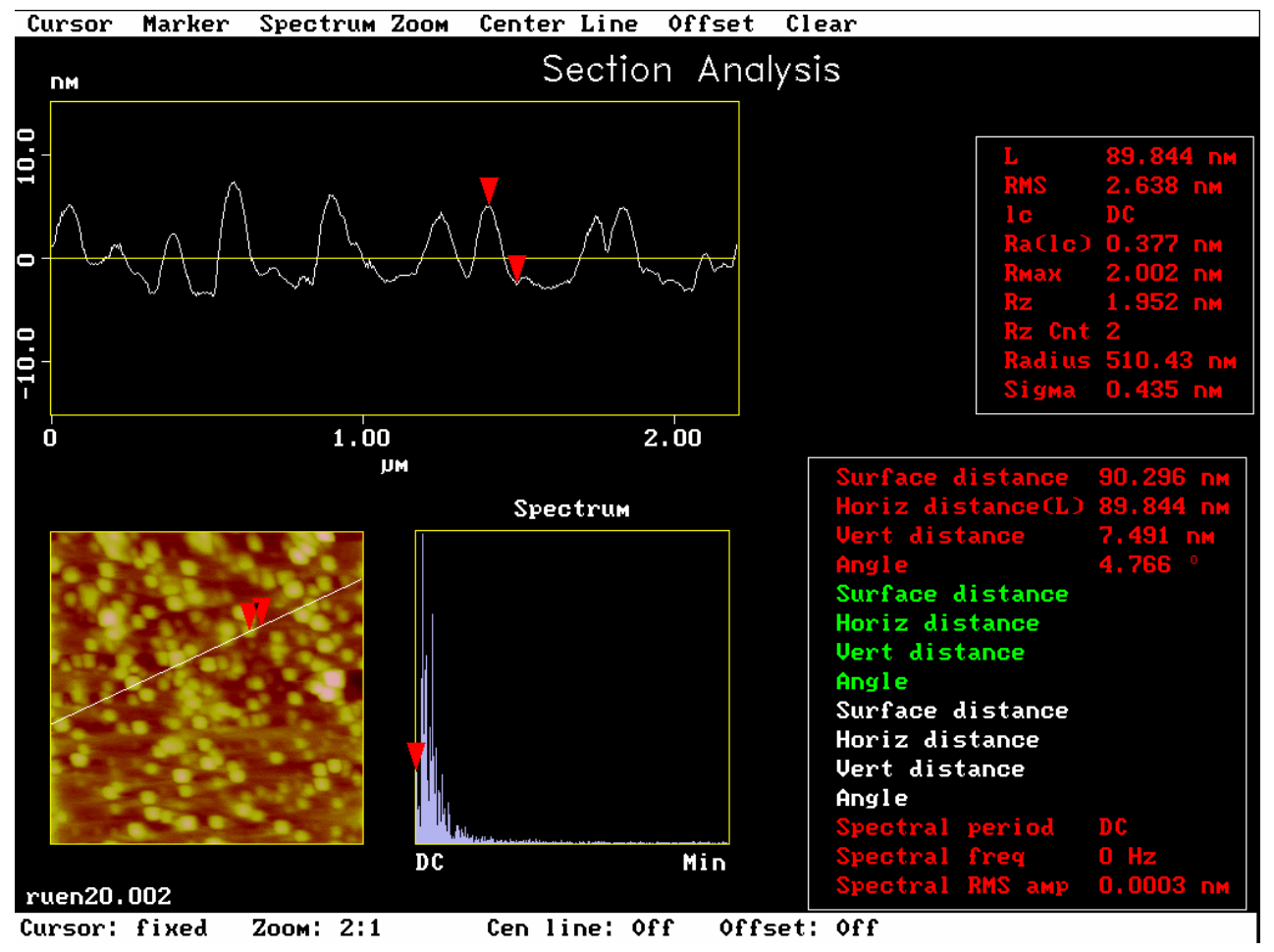

Figure S3. An AFM image of monolayer film of $\mathbf{1}$ deposited at $20 \mathrm{mN} \mathrm{m}^{-1}$. 


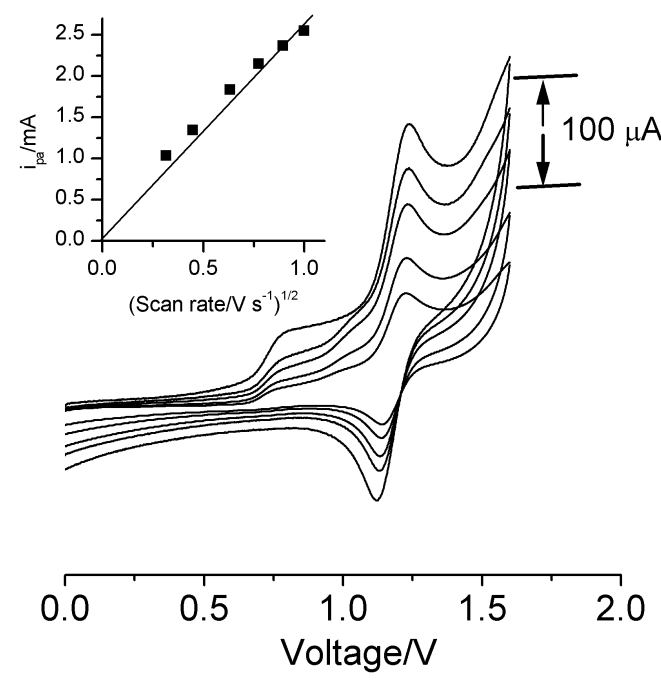

Figure S4. Cyclic voltammograms of $\mathbf{1}$ in $\mathrm{CH}_{3} \mathrm{CN}$ at scan rates of $0.25-1.0 \mathrm{~V} \mathrm{~s}^{-1}$. 